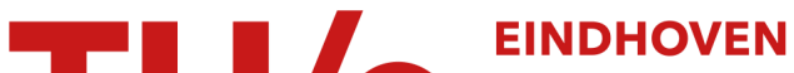 \\ UNIVERSITY OF \\ TECHNOLOGY
}

\section{Impulse efficiency of ground electrodes}

Citation for published version (APA):

Grcev, L. (2009). Impulse efficiency of ground electrodes. IEEE Transactions on Power Delivery, 24(1), 441-451. https://doi.org/10.1109/TPWRD.2008.923396

DOI:

10.1109/TPWRD.2008.923396

Document status and date:

Published: 01/01/2009

\section{Document Version:}

Publisher's PDF, also known as Version of Record (includes final page, issue and volume numbers)

\section{Please check the document version of this publication:}

- A submitted manuscript is the version of the article upon submission and before peer-review. There can be important differences between the submitted version and the official published version of record. People interested in the research are advised to contact the author for the final version of the publication, or visit the $\mathrm{DOI}$ to the publisher's website.

- The final author version and the galley proof are versions of the publication after peer review.

- The final published version features the final layout of the paper including the volume, issue and page numbers.

Link to publication

\section{General rights}

Copyright and moral rights for the publications made accessible in the public portal are retained by the authors and/or other copyright owners and it is a condition of accessing publications that users recognise and abide by the legal requirements associated with these rights.

- Users may download and print one copy of any publication from the public portal for the purpose of private study or research.

- You may not further distribute the material or use it for any profit-making activity or commercial gain

- You may freely distribute the URL identifying the publication in the public portal.

If the publication is distributed under the terms of Article 25fa of the Dutch Copyright Act, indicated by the "Taverne" license above, please follow below link for the End User Agreement:

www.tue.nl/taverne

Take down policy

If you believe that this document breaches copyright please contact us at:

openaccess@tue.nl

providing details and we will investigate your claim. 


\title{
Impulse Efficiency of Ground Electrodes
}

\author{
Leonid Grcev, Senior Member, IEEE
}

\begin{abstract}
The lightning current waveform has a major influence on the dynamic performance of ground electrodes. While high lightning current intensity improves the dynamic grounding performance due to ionization of the soil, very fast fronted pulses might worsen the performance in case of inductive behavior. The previous analysis has often been based on quasistatic approximation that is not applicable to very fast fronted pulses. To extend the analysis to fast fronted pulses in this paper, the full-wave analysis method based on the rigorous electromagnetic-field theory approach is used. In addition, realistic lightning current waveforms are applied, which reproduce the observed concave rising portion of typical recorded lightning current pulses. Based on the simulation results, new empirical formulas applicable for slow and very fast fronted lightning current pulses are proposed. The effects of the ionization of the soil are disregarded; therefore, the new formulas are applicable for a conservative estimate of the upper bound of the impulse impedance of ground electrodes.
\end{abstract}

Index Terms-Frequency response, grounding electrodes, modeling, power system lightning effects, transient response.

\section{INTRODUCTION}

$\mathbf{S}$ IMPLE arrangements of vertical and horizontal ground electrodes are often used for the lightning protection system earth termination [1]. Their basic function is to disperse the lightning current to earth without causing any potential differences or induced voltages that might endanger people or damage installations [2]. Grounding systems behavior is well understood at power frequency and detailed procedures for their design are widely accepted [3]. However, during lightning strokes the grounding systems performance might be quite different, and in some cases it can critically deteriorate the efficiency of the protection. In spite of the large amount of work that has been devoted to this subject, there is still no consensus on how to apply present knowledge to the design of the actual grounding for better high frequency and dynamic performance [4]. It is worth noting that the potential rise of the grounding systems of transformers, poles or lightning protective devices under the influence of a lightning return stroke is one of the main sources of overvoltages on the MV and LV installations [5].

Pioneering but comprehensive work on this subject was conducted in the first half of the twentieth century, which is sum-

Manuscript received October 30, 2006; revised May 11, 2007. First published May 12, 2008; current version published December 24, 2008. This work was supported in part by the Republic of Macedonia Ministry of Education and Science, in part by the Eindhoven University of Technology, Eindhoven, The Netherlands, and by the Swiss Federal Institute of Technology, Lausanne, Switzerland. Paper no. TPWRD-00667-2006.

The author is with the Faculty of Electrical Engineering, Ss. Cyril and Methodius University, 1000 Skopje, Macedonia (e-mail: leonid.grcev@ieee. org).

Digital Object Identifier 10.1109/TPWRD.2008.923396 marized by Sunde in the well known reference book [6]. Important pioneering work is described also in [7] and [8]. More recent work is summarized in the books [9] and [10]. There is a lack of carefully documented experimental work of which noteworthy examples are [11]-[14]. Recently computerized analysis methods have been developed based on different approaches, for example, on circuit theory [15]-[19], transmission line theory [21]-[27], electromagnetic field theory [28]-[37], and hybrid methods [38]-[40].

On the other hand, simply defined quantities that characterize deviation of the surge from the power frequency behavior are required for practical design of grounding systems [1]. Such quantities must be related to the factors with dominant influence on the ground electrodes' dynamic behavior. As it is generally known, impulse performance of ground electrodes depends mostly on three categories of factors, related to

- ground electrodes' geometry;

- soil's electrical properties;

- lightning current waveform properties.

Related to the latter, the main influence has

- current intensity;

- current pulse front time.

Different approaches have been used in the literature to derive simple formulas for the grounding impulse parameters, for example, based on experimental methods [42], [43], and simplified circuit analysis [1], [22], [41]. However, the latter are based on the quasi-static approximation, which constrains the applicability to slow fronted pulses. As a consequence, it has been shown in [52] that commonly used formulas in [1], [41], are not applicable for front times less that $1-\mu \mathrm{s}$. In addition, previous approaches use unrealistic lightning current waveforms approximated by cosine [41] or exponential functions [43] that are characterized by a convex wave front with a maximum current derivative at $t=0$.

This paper improves the analysis in the following two important points. First, it applies the full-wave analysis method applicable for both slow and very fast fronted lightning current pulses based on the rigorous electromagnetic field theory approach [32]-[35]. This analytical method is considered as the most accurate since it is based on least neglects in comparison to the methods based on transmission line and circuit theory [45], [46]. The results by this method have been validated by comparison with experimental results, especially with the extensive set of field measurements performed during nearly 30 years by the Électricité de France, [11], [12], [47] (for example in [35] and [48]). Another advantage of the electromagnetic over circuit methods is that it takes rigorously into account the electromagnetic interactions between elements of the ground electrode arrangements. 
Secondly, realistic lightning current pulse waveforms [49], [50] are used, which reproduce the observed concave rising portion of typical recorded lightning current pulses [51].

Such improved analysis led to new simple formulas for the impulse coefficient and the ground electrode effective length applicable for both slow and fast fronted lightning current pulses. The new formulas are compared with similar published by other authors and with experimental results. A numerical example is added that illustrates its practical use.

In this paper the influence of the high current intensity that practically improves the impulse grounding performance is not taken into account, which is an approach adopted by many researchers, for example, [10], [22], [26], [27], [29], [30]. In case of high lightning currents the electric field at the ground electrodes may become larger than the electric strength of the soil, resulting in breakdown and sparks discharge. This usually improves the grounding performance, especially in less conductive soil. There is no consensus on the simple formulas that take into account the influence of this complex and irregular process, since they are constrained by the necessary underlying simplifications and assumptions [44]. For example, the traditional model [54] assumes uniform ionization in a volume around ground electrode in which resistivity of the soil reach the resistivity of the electrode conductor. Recent models include effects of measured residual resistivity of the soil in the ionized region [44] and observed effects of discrete breakdowns and filamentary arc paths [16]. However, it is also a matter of discussion if a single value of the critical electric field can be assumed for all types and conditions of the soil, since values in the range of $70-2700 \mathrm{kV} / \mathrm{m}$ have been reported, for example, [15], [56], [57].

The neglect of the soil ionization effects in this paper leads to the conservative upper bound of the impulse grounding resistance. Although the influence of the current intensity is not taken into account, if desired, it can be simply added to the new formulas by reduction factors developed by other authors, for example in [1] and [43].

\section{DyNAMIC Behavior OF GROUND ElECTRODES}

The dynamic behavior of ground electrodes can be visually analyzed by computer animation using dedicated software [58]. Fig. 1 shows snapshots at 6 moments of time $(t=0.1-\mu \mathrm{s}$, $0.5-\mu \mathrm{s}, 1-\mu \mathrm{s}, 5-\mu \mathrm{s}, 10-\mu \mathrm{s}$ and $50-\mu \mathrm{s})$ of the potential pulse propagation along a $60-\mathrm{m}$ horizontal wire when a current pulse is injected in the wire's left end. ${ }^{1}$ Fig. 1 shows the influence of the soil resistivity $\rho$ for the three cases: a) $\rho=10-\Omega \mathrm{m}$; b) $\rho=100-\Omega \mathrm{m}$; and c) $\rho=1000-\Omega \mathrm{m}$. In these and all other examples in this paper a median value of the soil's relative permittivity $\varepsilon_{r}=10$ is adopted. The analysis in the paper is focused on the dominant influence of the soil resistivity, which is also an approach adopted in other simple formulas for the dynamic grounding characteristics [1], [22], [41]-[43]. In all cases, the injected current pulse is with peak value $I_{m}=1$-kA, zero-to peak time $T_{1}=1-\mu \mathrm{s}$, and half-width $T_{2}=50-\mu \mathrm{s}$.

As it is generally known [8], due to the limited velocity of pulse propagation along the ground electrode, in the first mo-

\footnotetext{
${ }^{1}$ In this and all other examples in the paper, the influence of the current intensity on the dynamic behavior is disregarded.
}

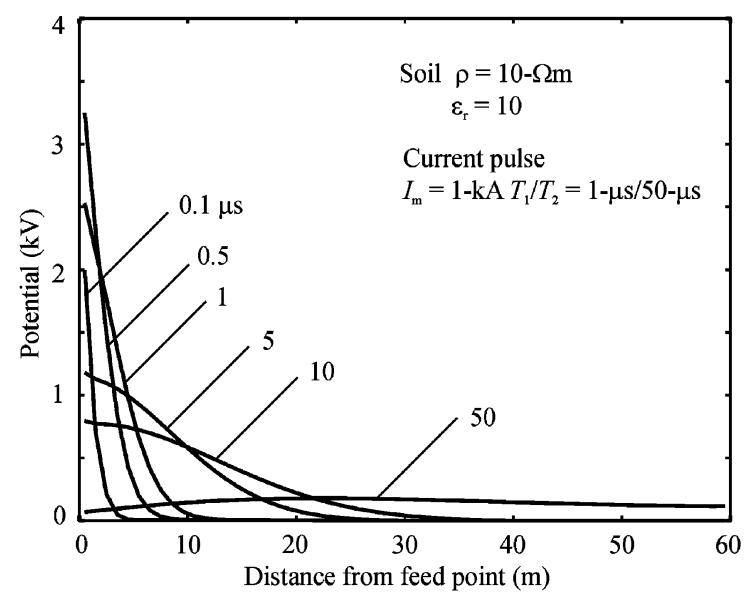

(a)

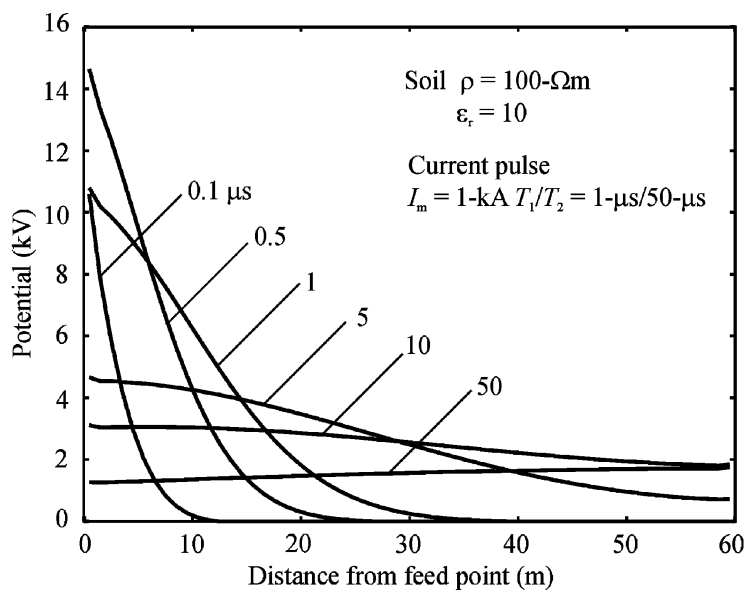

(b)

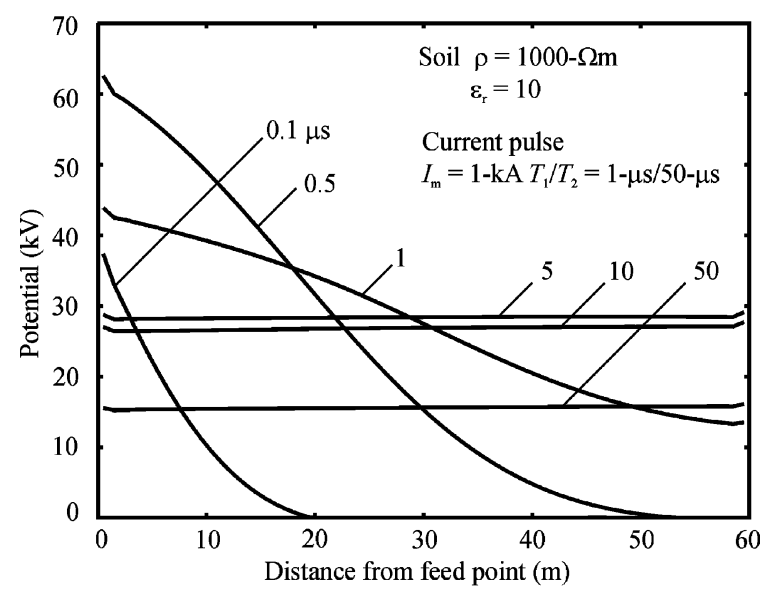

(c)

Fig. 1. Potential pulse propagation along $60-\mathrm{m}$ horizontal ground wire when a current pulse, $I_{m}=1-\mathrm{kA}, T_{1} / T_{2}=1-\mu \mathrm{s} / 50-\mu \mathrm{s}$, is injected in wire's left end.

ments the current is dispersed into the ground through a small part of the electrode near the feed point, which leads to high values of conductor potential there. Such velocity is not uniform since it reduces with time [8].

The resistivity of the soil has large influence on the pulse propagation. It can be seen that in high conductive soil with $\rho=10-\Omega \mathrm{m}$, Fig. 1(a), the average pulse propagation velocity 


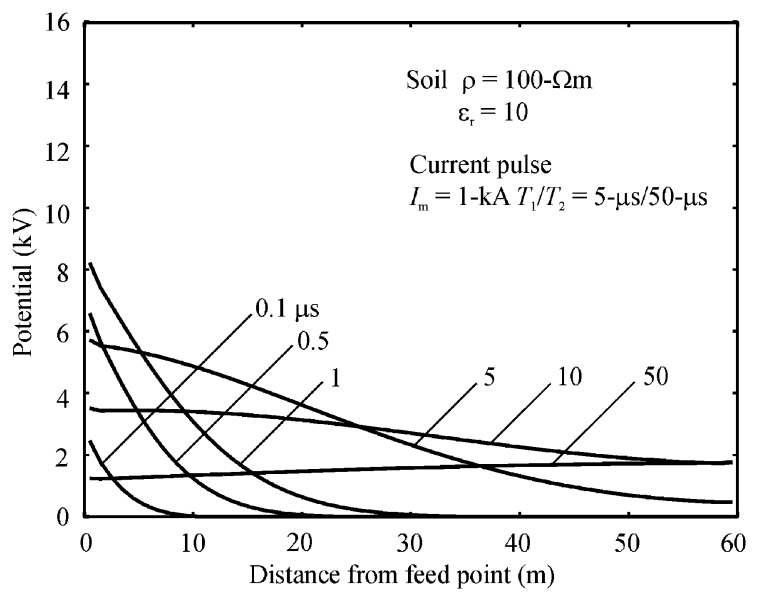

Fig. 2. Influence of the slow fronted current pulse with $T_{1}=5-\mu$ s on potential pulse propagation along $60-\mathrm{m}$ horizontal ground wire.

in the first $0.5-\mu \mathrm{s}$ is very low, about $0.05 \mathrm{c}$ (where $c$ is speed of light). In case of soil with $\rho=100-\Omega \mathrm{m}$, Fig. 1(b), such velocity is about $0.15 \mathrm{c}$, and in high resistive soil, $\rho=1000-\Omega \mathrm{m}$, Fig. 1(c), it is much higher, about $0.33 \mathrm{c}$.

Two periods can be distinguished: the first one before the pulse has reached the other end of the wire, characterized by an uneven potential distribution along the wire, and the second one shortly after the pulse has reached the other end of the wire, the latter characterized by a nearly equipotential distribution typical for low frequencies. We refer to the first period as a fast transient period and to the second period as a slow transient period.

The duration of the fast transient period depends on the pulse propagation velocity and the electrode length. For the $60-\mathrm{m}$ wire in case of high conductive soil with $\rho=10-\Omega \mathrm{m}$, Fig. 1(a), the duration of the fast transient period is about $50-\mu \mathrm{s}$, in the case of $\rho=100-\Omega \mathrm{m}$, Fig. 1(b), it is about $15-\mu \mathrm{s}$, and in high resistive soil, with $\rho=1000-\Omega \mathrm{m}$, Fig. 1(c), it is much smaller, about $5-\mu \mathrm{s}$.

The potential at the feed point reaches its peak value at about $t=0.3-\mu \mathrm{s}$ in all three cases in Fig. 1. After that the values of the potential are gradually reduced to their low frequency values. The maximal deviation of the potential at the feed point from its low frequency value is highest in high conductive soil. In the case in Fig. 1(a) with $\rho=10-\Omega \mathrm{m}$, the potential peak value is about 11 times higher that at low frequencies. In the case of $\rho=100-\Omega \mathrm{m}$, Fig. 1(b), it is about 5 times higher, and in high resistive soil, $\rho=1000-\Omega \mathrm{m}$, Fig. 1 (c), only about 2 times higher. This trend is increased for longer conductors. Therefore, it appears that long ground electrodes in conductive soil, have worst impulse performance, but it should be emphasized that it is only relative to their very good low frequency performance.

It should be also emphasized that the deviation from the low frequency behavior lasts only during the fast transient period, which might be very short, especially in low conductive soil. After that, during the slow transient period, the groundings' behavior is practically equivalent to the low frequency performance.

Fig. 2 shows the influence of the slow fronted current pulse. Here, the pulse is with zero-to-peak time $T_{1}=5-\mu \mathrm{s}$. This figure should be compared with Fig. 1(b) since in both cases the soil has the same resistivity, $\rho=100-\Omega \mathrm{m}$. The velocity of the pulse propagation is the same in both cases. However, the faster fronted current pulse in Fig. 1(b) results in larger potentials at feed point in the first moments because larger currents are forced to disperse into the ground through small parts of the electrode.

These examples illustrate the importance of the potential at feed point that characterizes the dynamic performance. However, they also indicate that the duration of the fast transient period is very important since all dynamic characteristics are related only to this period.

\section{Quantities That Characterize the DynamiC BEHAVIOR OF GROUND ELECTRODES}

There is no consensus in the literature on the designations and definitions of the quantities used to characterize the dynamic behavior of ground electrodes [52]. Furthermore, different methods and underlying assumptions make difficult the comparisons between the results.

One of the main objectives of the quantities that characterize the grounding dynamic behavior is to determine the deviation of the dynamic from the low frequency performance. The basic quantity that characterizes the low frequency performance is the low frequency resistance defined as

- $R=V / I$, where $V$ is the voltage between the feed point at the grounding system and the point at remote neutral ground and $I$ is the injected current. For typical grounding systems $V$ is practically equal to the electric potential with a reference point at the remote neutral ground [38]. It is important to emphasize that the low frequency resistance $R$ also characterizes the performance in the slow transient period, which is usually a larger part of the total lightning stroke duration.

The following definitions of the impulse characteristics are adopted in this paper:

- Transient impedance: $z(t)=v(t) / i(t)$, where $v(t)$ is electric scalar potential at the feed point in reference to remote neutral ground and $i(t)$ is the injected current pulse.

- Impulse impedance: $Z=V_{m} / I_{m}$, where $V_{m}$ is the peak value of the potential pulse $v(t)$ and $I_{m}$ is the peak value of the injected current pulse $i(t)$.

- Impulse coefficient: $A=Z / R$, where $Z$ is the impulse impedance and $R$ is the low frequency resistance.

- Effective length: $\ell_{e f f}$ is the maximal length of the ground electrode for which the impulse coefficient $A$ is equal to one, and above which the impulse coefficient $A$ is larger than one.

- Duration of the fast transient period-time when the transient impedance reach the value of the low frequency resistance.

It is worth noting that above quantities are traditionally coined as "impedances" [2], [22], or as "resistances" [9], [14], [43], often with quite different definitions, for example: $Z=V_{m} / I_{V_{m}}$-where $I_{V_{m}}$ is current at the time of voltage peak $V_{m}$ in [16]; $Z=V_{I_{m}} / I_{m}$-where $V_{I_{m}}$ is voltage at the time of current peak $I_{m}$ in [9]; $Z=V / I$-where $V$ and $I$ are measured at $t=6 \mu \mathrm{s}$ in [56]. 


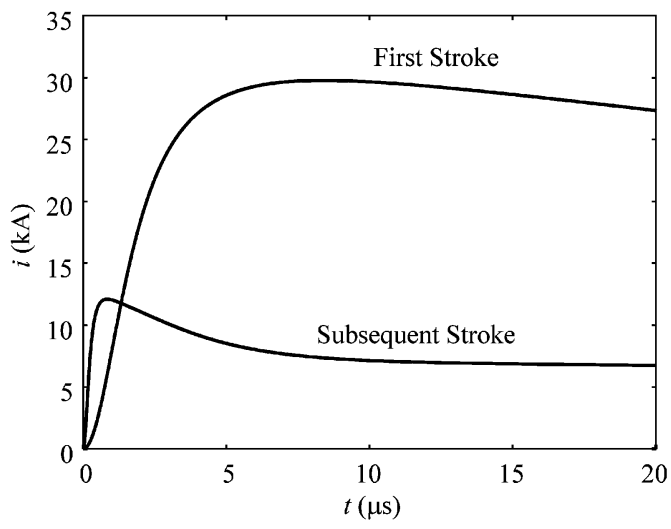

(a)

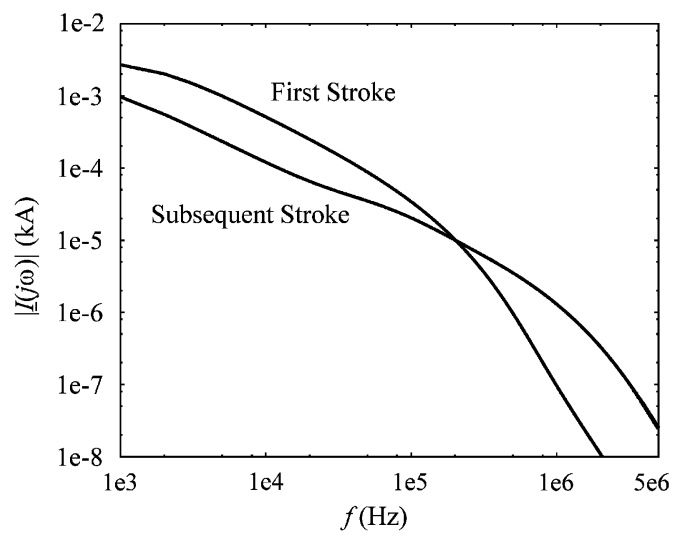

(b)

Fig. 3. (a) First and subsequent return stroke current waveforms (adapted from [49]) and (b) their frequency spectrum.

In addition the harmonic impedance is very useful in transient analysis [11], [28]. It does not depend on the excitation and it depends solely on geometry and electromagnetic characteristics of the ground electrodes and the medium.

- Harmonic impedance: $\underline{Z}(j \omega)=\underline{V}(j \omega) / \underline{I}(j \omega)$, where $\underline{V}(j \omega)$ and $\underline{I}(j \omega)$ are phasors of the steady state harmonic electric potential at the feed point in reference to the remote neutral ground and the injected current, respectively, in a frequency range from $0-\mathrm{Hz}$ up to the highest frequency of interest in transient studies.

\section{AdOPTEd LightNing CURRENT WaVEForms OF TyPiCAL First AND SUbSEQUENT STROKE}

In this study we have used two lightning current waveforms corresponding to the typical first and subsequent return strokes, based on observations of Berger et al. [51], according to [49] and [5], Fig. 3(a).

The current waveforms are chosen by Rachidi et al. [49] to fit typical experimental data and are reproduced by means of a sum of Heidler's functions [50]

$$
i(t)=\frac{I_{0}}{\eta} \frac{\left(\frac{t}{\tau_{1}}\right)^{n}}{1+\left(\frac{t}{\tau_{1}}\right)^{n}} e^{\left(-t / \tau_{2}\right)}, \quad \eta=e^{-\left(\tau_{1} / \tau_{2}\right)\left(n\left(\tau_{2} / \tau_{1}\right)\right)^{1 / n}}
$$

where $I_{0}$ is the amplitude of the current pulse; $\tau_{1}$ is the front time constant; $\tau_{2}$ is the decay time constant; $n$ is exponent having values between 2 to 10 ; and $\eta$ is the amplitude correction factor.
TABLE I

Parameters of the Two HeIDLER's Functions Used to ReProduce the LightNING CURRENT WAVEFORMS IN FIG. 3(A)

\begin{tabular}{lcccc}
\hline & $I_{0}(\mathrm{kA})$ & $\tau_{1}(\mu \mathrm{s})$ & $\tau_{2}(\mu \mathrm{s})$ & $n$ \\
\hline First Stroke & 28 & 1.8 & 95 & 2 \\
Subsequent & 10.7 & 0.25 & 2.5 & 2 \\
Stroke & 6.5 & 2 & 230 & 2 \\
\hline
\end{tabular}

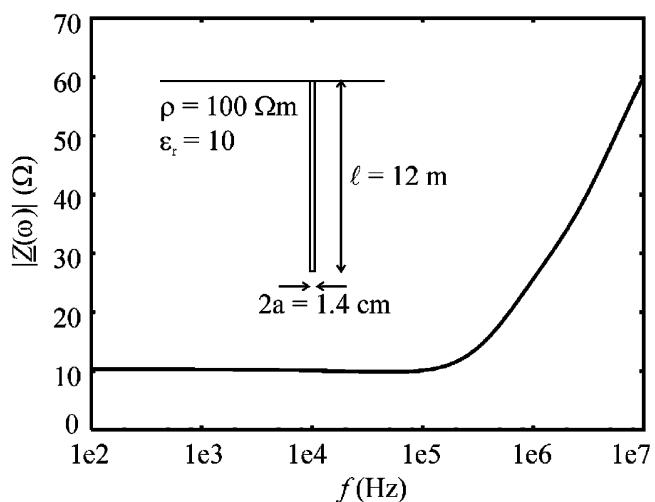

Fig. 4. Amplitude of the harmonic grounding impedance of a 12-m vertical rod.

The first stroke waveform is reproduced by one and subsequent stroke by a sum of two Heidler's functions with parameters given in Table I [49].

The first return-stroke current pulse is characterized by a peak value of $30 \mathrm{kA}$, zero-to-peak time of about $8-\mu \mathrm{s}$ and a maximum steepness of $12 \mathrm{kA} / \mu \mathrm{s}$, whereas the subsequent return stroke current has a peak value of $12 \mathrm{kA}$, zero-to-peak time of about $0.8-\mu \mathrm{s}$ and a maximum steepness of $40 \mathrm{kA} / \mu \mathrm{s}$.

Fig. 3(b) presents the frequency spectrum, that is, the magnitude of the Fourier transform of the typical lightning current waveforms. It is clear that subsequent stroke, which has larger rate of rise of the front, has higher frequency content in comparison with the first stroke.

\section{Influence of the CuRrent Pulse Front Time ON THE DYNAMIC CHARACTERISTICS}

We consider a 12-m long vertical rod constructed of copper with $0.7-\mathrm{cm}$ radius in earth with $100-\Omega \mathrm{m}$ resistivity and relative permittivity of 10. Fig. 4 shows the magnitude of the harmonic impedance. The harmonic impedance $\underline{Z}(j \omega)$ is frequency independent and equal to the low frequency resistance to ground, $R=10.3-\Omega$, in the low frequency (LF) range up to a frequency of about $100 \mathrm{kHz}$. In the high frequency (HF) range it exhibits inductive behavior and its value becomes larger than $R$ (Fig. 4).

Fig. 5(a) shows the first stroke lightning current pulse $i(t)$ injected in the same vertical rod, and the response to this excitation: the potential at the feed point $v(t)$, and the transient impedance $z(t)$. The potential $v(t)$ may be interpreted as a response to the excitation $i(t)$ passed through a "filter" with a frequency characteristic given by the harmonic impedance $\underline{Z}(j \omega)$ in Fig. 4. The first stroke current pulse $i(t)$, does not have enough frequency content in the HF range (above about $100 \mathrm{kHz}$ ), and consequently is not affected by the HF inductive 


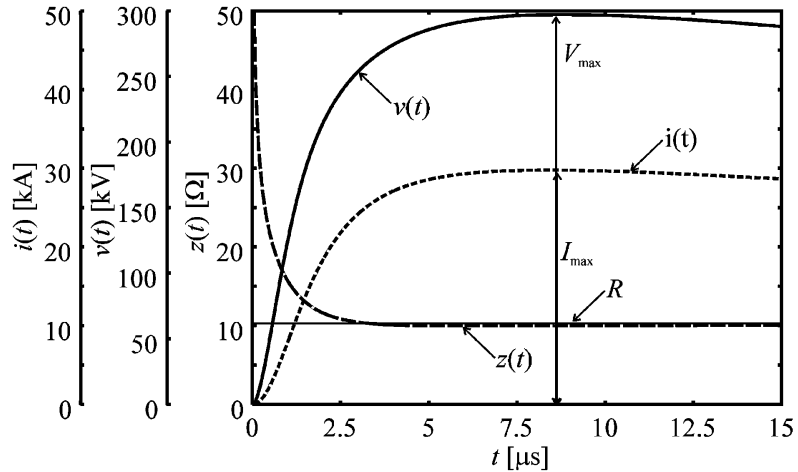

(a)

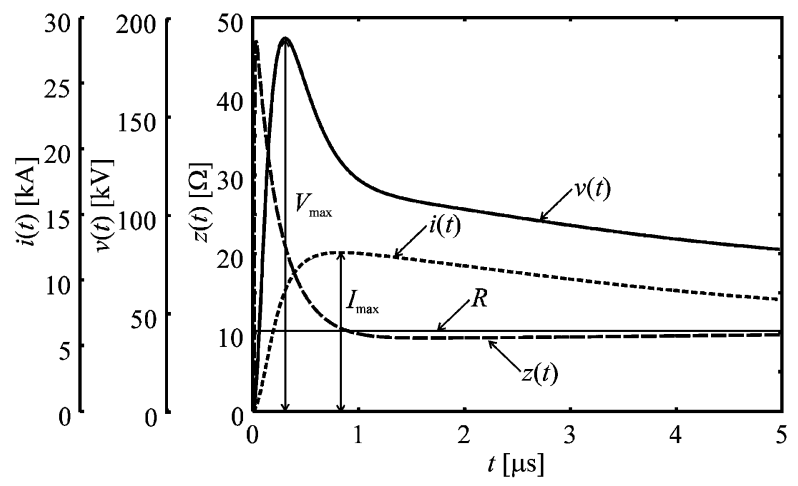

(b)

Fig. 5. Lightning current pulse $i(t)$, transient potential at feed point $v(t)$ and ground impedance of 12-m ground rod. (a) Response to typical first stroke current pulse. (b) Response to typical subsequent stroke current pulse.

part of $\underline{Z}(j \omega)$ (Fig. 4). The response is substantially determined by the frequency independent part of $Z(\omega)$ equal to the LF resistance $R$ (Fig. 4). As a result, the potential pulse waveform $v(t)$, is not significantly modified in comparison to the current pulse waveform $i(t)$ and their maximums occur at the same time [Fig. 5(a)]. Although the transient impedance $z(t)$ goes very fast to some high value (larger than $50-\Omega$ ) it quickly settles to the $\mathrm{LF}$ resistance value $(R=10.3-\Omega)$. This determines the duration of the fast transient period to about $3-\mu \mathrm{s}$. Therefore, after $t=3 \mu \mathrm{s}$, that is, in the slow transient period the behavior is determined solely by the LF resistance $R$. As a result, the impulse impedance is equal to the low frequency resistance $Z=R$, and the impulse coefficient $A$ is equal to one.

For the subsequent stroke current pulse injected in the same vertical rod (Fig. 4) the situation is different, Fig. 5(b). The subsequent stroke current pulse has much steeper front than the first stroke. As a result, it has significant frequency content above $100-\mathrm{kHz}$ and therefore the response is influenced by the HF inductive part of the $\underline{Z}(j \omega)$ (Fig. 4). The "filter" amplifies the HF components of the current pulse, which results in a large peak $V_{m}$ [Fig. 5(b)] of the transient potential $v(t)$. Typically for inductive behavior, the voltage pulse precedes the current pulse. This causes larger value of the impulse impedance, $Z=15.7-\Omega$, than the low frequency resistance, $R=10.3-\Omega$, and the impulse coefficient $A$ of about 1.5. The transient impedance $z(t)$ similarly to the case of the first stroke [Fig. 5(a)] rises very rapidly to a high value (of about $47-\Omega$ ), but also quickly (in about $1-\mu \mathrm{s}$ ) settles to values near the low frequency value $(R=10.3-\Omega)$.

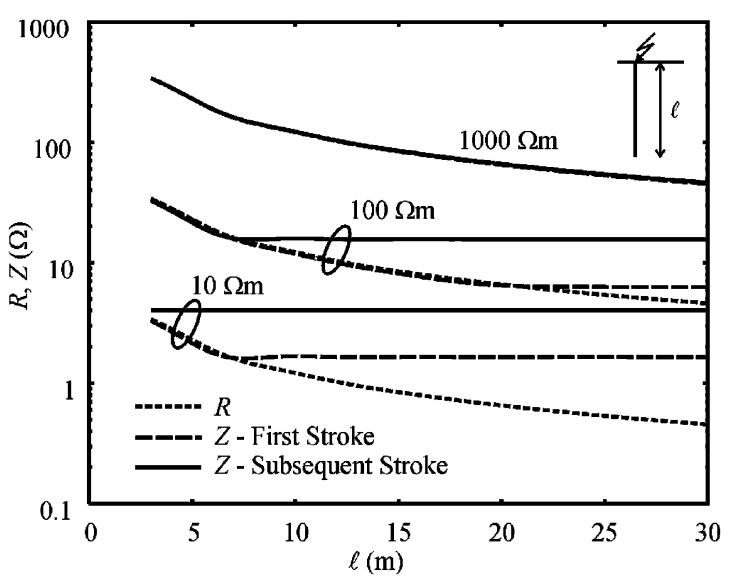

Fig. 6. Low-frequency ground resistance $R$ and impulse impedance $Z$ of vertical ground electrode with lengths from 3 to $30-\mathrm{m}$, earth resistivity: 10,100 , and $1000-\Omega \mathrm{m}$ and first and subsequent stroke lighting current waveforms [Fig. 3(a)].

Therefore, the fast transient period lasts only about $1-\mu \mathrm{s}$. After that the slow transient behavior is determined solely by the LF resistance $R$.

The examples in Figs. 4 and 5 illustrate the fact that HF inductive behavior of the grounding might result in large peaks of the transient potential at the feed point in cases when the lightning current pulses have enough high frequency content to be influenced by such inductive behavior.

\section{IMPULSE IMPEDANCE AND EFFECTIVE LENGTH}

Fig. 6 shows the simulation results of the LF ground resistance $R$ and the impulse impedance $Z$ of the vertical ground electrode with lengths in a range from $3-\mathrm{m}$ to $30-\mathrm{m}$ in earth with resistivity: $10-\Omega \mathrm{m}, 100-\Omega \mathrm{m}$, and $1000-\Omega \mathrm{m}$ and for lightning current waveforms related to the first and the subsequent strokes [Fig. 3(a)].

The impulse impedance of ground electrodes with smaller length is equal to the LF ground resistance, that is, the impulse coefficient is equal to one. The impulse impedance decreases with increase of electrode length, but at a certain length it becomes constant, while the LF resistance continues to decrease resulting in impulse coefficient larger than one. Therefore, only a certain electrode length is effective in controlling the impulse impedance, which is referred as effective length $\ell_{e f f}$. So the effective length $\ell_{e f f}$ can be defined as a maximal electrode length for which the impulse coefficient is equal to one. The effective length is larger for more resistive earth and slow fronted currents pulses, such as the first stroke current pulse. Similar trends have been observed elsewhere, for example in [41].

The meaning of the effective length is illustrated also in Fig. 7. Fig. 7 shows the potential at feed point of the ground electrodes with different lengths in soil with resistivity $\rho=100-\Omega \mathrm{m}$ for the subsequent stroke lightning current waveform injected in the electrodes' end. The effective length can be estimated as about $\ell_{\text {eff }}=7.5-\mathrm{m}$. Shorter electrodes then $\ell_{\text {eff }}$ have resistive behavior. As a result, the potential and the current waveforms are practically identical, the impulse impedance is equal to $R$, and impulse coefficient is equal to one. 


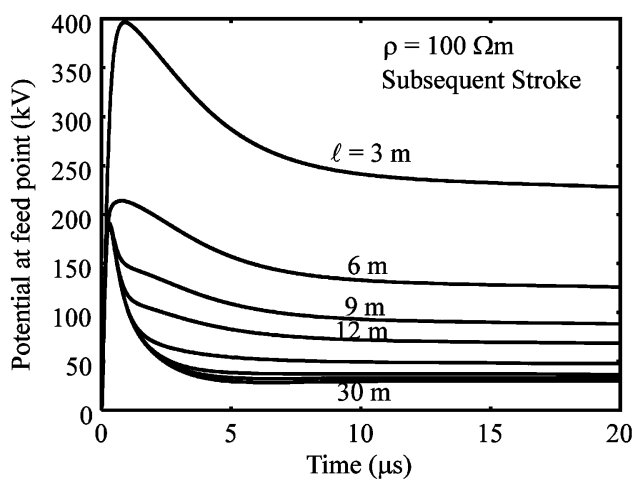

Fig. 7. Influence of the ground electrode length on the potential at feed point.

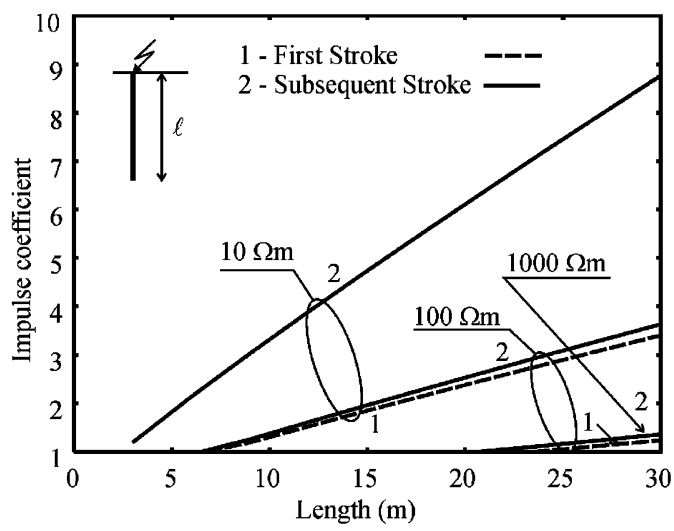

Fig. 8. Impulse coefficients of a single vertical ground electrode.

For longer electrodes than $\ell_{e f f}$, due to the influence of the inductive behavior, the potential pulse is modified with a characteristic peak $V_{m}$ that is independent of the electrodes' length. Although $V_{m}$ remains constant, differences between $V_{m}$ and the potential in the slow transient period, which is equivalent to the LF potential, are becoming larger with longer electrodes. As a result, although the performance in the slow transient period is better, the performance in the fast transient period remains the same. As a result, the impulse impedance is larger that $R$ and impulse coefficient is larger that one. Therefore, larger values of the impulse coefficient do not automatically mean that the performance is worse, since they may be a result of low values of $R$. As a conclusion, to get the complete picture the impulse coefficient, which is a relative quantity, should be always used in combination with the low frequency resistivity $R$.

\section{IMPULSE COEFFiciENT OF A Single VerticAl AND HORIZONTAL ELECTRODE}

The impulse coefficient of a single vertical and horizontal ground electrode as a function of the electrode length is illustrated in Figs. 8 and 9, respectively.

Different cases are illustrated for earth resistance values of 10 , 100 , and $1000-\Omega \mathrm{m}$ and for the first and subsequent stroke current pulses. Impulse performance is worse for longer electrodes in better conductive earth and for faster fronted pulses, such as subsequent strokes. Horizontal electrodes are slightly less effective at power frequency in comparison to vertical ones, but have

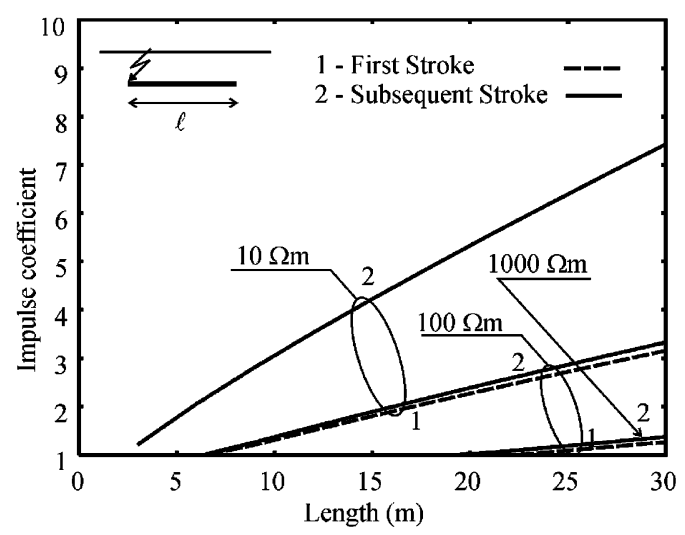

Fig. 9. Impulse coefficients of a single horizontal ground electrode.

TABLE II

VALUES OF $\alpha$ AND $\beta$ IN (1) FOR A SINGLE VERTICAL GROUND ELECTRODE

\begin{tabular}{ccc}
\hline $\begin{array}{c}\text { Lightning Stroke }- \\
\text { Earth' Resistivity }\end{array}$ & $\alpha(1 / \mathrm{m})$ & $\beta$ \\
\hline $\begin{array}{c}\text { Subsequent Stroke }-10 \Omega \mathrm{m} \\
\text { First Stroke }-10 \Omega \mathrm{m}\end{array}$ & 0.27 & 0.67 \\
$\begin{array}{c}\text { Subsequent Stroke }-100 \Omega \mathrm{m} \\
\text { First Stroke }-100 \Omega \mathrm{m}\end{array}$ & 0.105 & 0.25 \\
Subsequent Stroke $-1000 \Omega \mathrm{m}$ & 0.0355 & 0.17 \\
\hline
\end{tabular}

better impulse efficiency; however, both exhibit very similar behaviors. Taking into account necessary simplifications, results in Fig. 8 for the impulse coefficient of a vertical ground electrode can be used also as a conservative estimate of the impulse coefficient of horizontal electrodes.

When the electrode length is less or equal than $\ell_{e f f}$ then the impulse coefficient is equal to one

$$
A=1, \quad\left(\ell \leq \ell_{e f f}\right) .
$$

For lengths equal and larger than the effective length, dependence of the impulse coefficient $A$ on the electrode length is nearly linear and may be approximated with a line

$$
A=\alpha \ell+\beta, \quad\left(\ell \geq \ell_{e f f}\right)
$$

where $\ell$ is in meters.

The effective length $\ell_{\text {eff }}$ may be determined for $A=1$

$$
\ell_{e f f}=\frac{1-\beta}{\alpha} \text {. }
$$

All dependences of the impulse coefficient $A$ for the cases illustrated in Fig. 8 may be approximated with three lines (3) with parameters given in Table II. The impulse coefficient for the both vertical and horizontal ground electrode for the first stroke in earth with resistivity $1000 \Omega \mathrm{m}$ may be approximated with $A=1$.

The coefficients $\alpha$ and $\beta$ can be approximated by the following formulas for other values of the earth resistivity $\rho$, in $\Omega \mathrm{m}$, and zero-to-peak time of the lightning current pulse $T_{1}$, in $\mu \mathrm{s}$, (Fig. 10)

$$
\begin{aligned}
& \alpha=0.025+e^{-0.82\left(\rho \cdot T_{1}\right)^{0.257}} \\
& \beta=0.17+e^{-0.22\left(\rho \cdot T_{1}\right)^{0.555}} .
\end{aligned}
$$




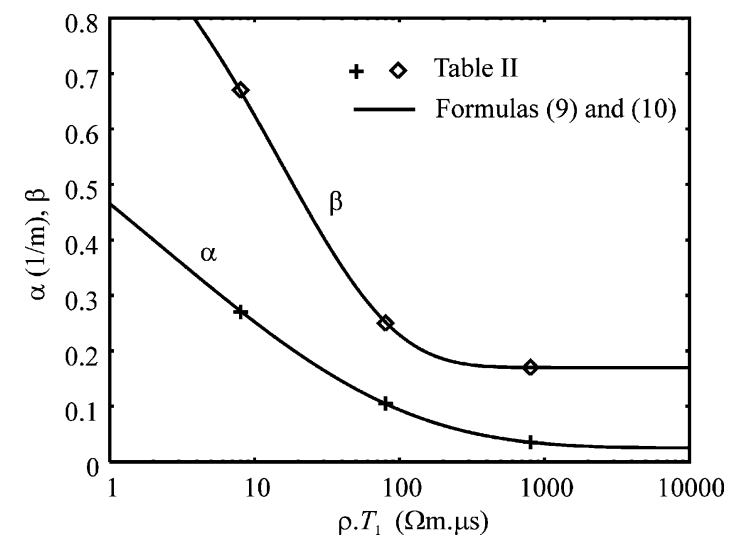

Fig. 10. Approximation of coefficients $\alpha$ (5) and $\beta$ (6). The abscissa axis indicates product of the earth resistivity $\rho$ in $\Omega \mathrm{m}$ and zero-to-peak time of the lightning current pulse $T_{1}$ in $\mu$ s.

All results are for $0.7-\mathrm{cm}$ electrode radius and 1-m depth of burial of the horizontal electrode, but since the results does not significantly depend on these parameters, formulas (2)-(6) can be used for a first approximation of other similar practically important cases.

\section{IMPULSE EFFICIENCY OF SOME TYPICAL GROUND ELECTRODE ARRANGEMENTS}

Multiple ground electrode arrangements improve the low-frequency ground resistance, but they also improve the impulse efficiency. The simulation results for several typical ground electrode arrangements illustrated in the first column of the Table III indicate very similar linear functions for the impulse coefficient as in Figs. 8 and 9, only the values are reduced by extents given in the Table III. The length $\ell(m)$ given in the first column of the Table III can be applied in (3), and the reduction factors in the second column of the Table III should be applied to both $\alpha$ and $\beta$, which yields the impulse coefficient (3) and the effective length (4). In addition, also impulse impedance and maximal transient ground potential rise can be obtained by formulas given in Part III of this paper. A numerical example of the application of above formulas is given in Appendix B.

It should be noted, however, that this is the conservative upper bound of the dynamic characteristics. Their reduction due to the soil ionization can be estimated, if desired, by reduction factors by other authors, for example [1] and [43].

It should be also emphasized that above mentioned dynamic characteristics are related to the fast transient period only. After that, in the slow transient period, the performance of the ground electrodes is practically identical with the low frequency performance and is characterized by low frequency grounding resistance $R$.

\section{Relation to Previous Work}

Formulas for impulse coefficient and effective length, when the soil ionization is neglected, have been given by Gupta and Thapar in [41], that is, for the effective length

$$
\ell_{e f f}=1.4 \sqrt{\rho T}
$$

TABLE III

REDUCTION FACTOR OF THE IMPULSE COEFFICIENT FOR MULTIPLE VERTICAL GROUND ELECTRODE ARRANGEMENTS

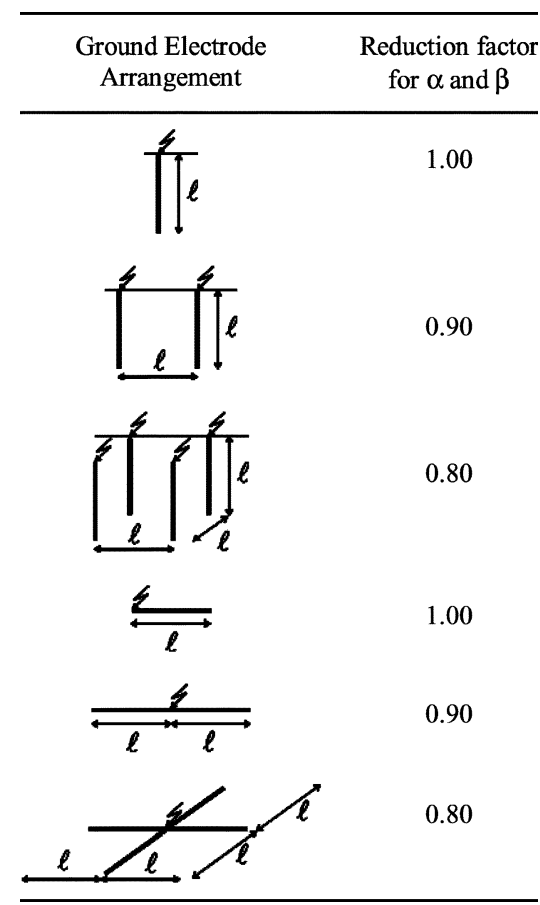

and for the impulse coefficient

$$
A=e^{0.333\left(\ell / \ell_{e f f}\right)^{2.3}} .
$$

However, it has to be noted that the current pulse in [41] has been approximated with a cosine function that has unrealistic convex front and a maximum current derivative at $t=0$. The comparison between the impulse coefficient obtained by (8) from [41] and the method proposed in this paper for a horizontal ground electrode is given in Fig. 11. Values for $T_{1}$ of $8.38 \mu \mathrm{s}$ and $0.835 \mu$ s are used in (5) and (6) for the first and subsequent stroke current pulses, respectively.

The comparison reveals agreement between the methods in more resistive earth and for smaller ground electrode lengths. In less resistive earth, for longer ground electrode, and for smaller zero-to-peak times of the lightning current pulses formulas in [41] greatly overestimate the impulse coefficient in comparison with the formula proposed in this paper.

\section{EXPERIMENTAL VERIFICATION}

Fig. 12 shows the oscillograms of the recorded current pulse injected at the end point of 14-m long horizontal ground wire and transient voltage to remote ground at the same point during field measurements performed by the Électricité de France [47]. This is one of rare results available in the literature with current waveform related to typical subsequent stroke. The electrode was constructed of a $116-\mathrm{mm}^{2}$ copper wire buried at $0.6-\mathrm{m}$ depth in soil with resistivity $70-\Omega \mathrm{m}$ and relative permittivity 15 . This experimental result has been previously compared with simulation results based on the electromagnetic field theory approach [48] (Fig. 12). 


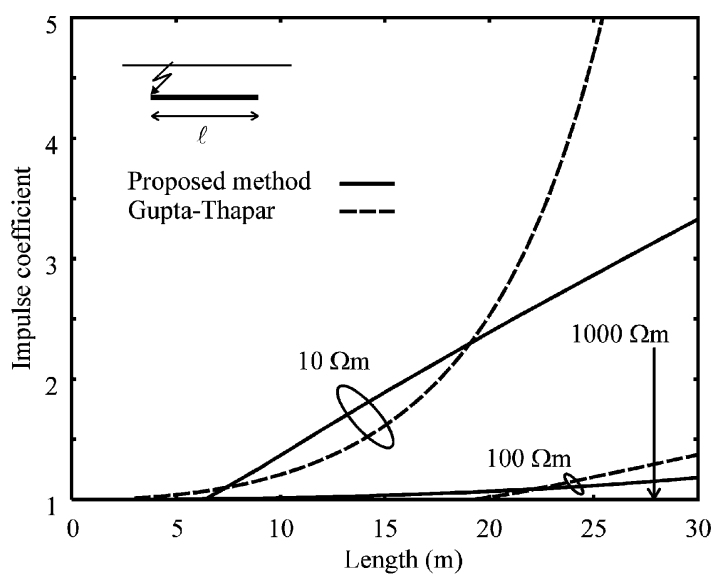

(a)

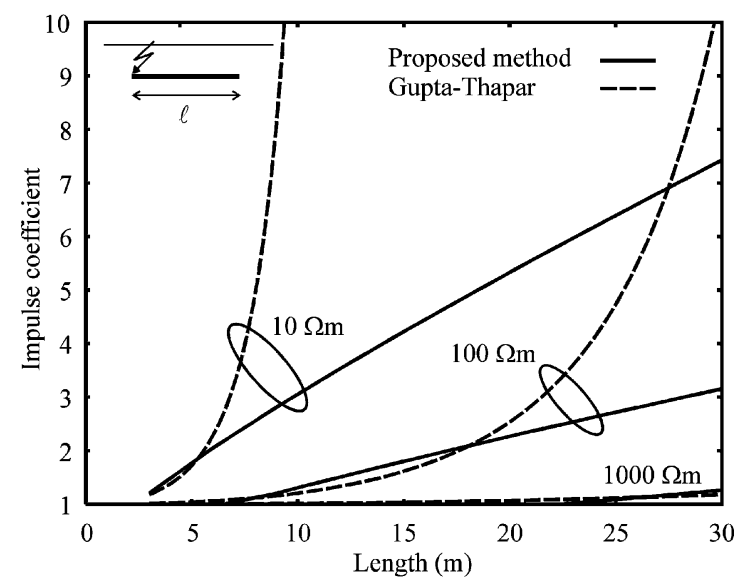

(b)

Fig. 11. Comparison between formulas for the impulse coefficient of horizontal ground electrode based on [41] and proposed in this paper. (a) First stroke. (b) Subsequent stroke.

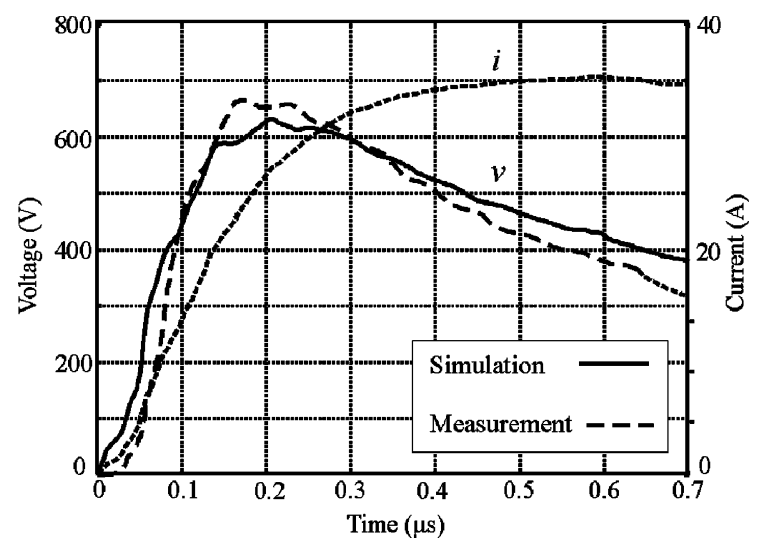

Fig. 12. Measurement and simulation of transient voltages to remote ground at the beginning point of $15 \mathrm{~m}$ long horizontal wire.

Recorded current and voltage pulses have maximums, $I_{m}=$ $35 \mathrm{~A}$ and $V_{m}=660 \mathrm{~V}$, respectively, which determines value of the impulse impedance $Z=18.8 \Omega$. Since the ground resistance is $R=7.2 \Omega$, the measured impulse coefficient is $A=2.6$.

The result of the application of the proposed formulas (2)-(6) for the impulse coefficient is $A=2.5$, which is consistent with the measurements.

On the other hand, application of the formulas [41] (5)-(6) gives the result for the impulse coefficient $A=2.1$.

\section{CONCLUSIONS}

1) Inductive phenomena effectively oppose discharge of fast fronted lightning current pulses through the ground electrodes into the earth. In many cases, longer electrodes especially in better conductive soil exhibit resistive behavior in the low frequency range and inductive behavior in the high frequency range (often above $100 \mathrm{kHz}$ ). When fast fronted lightning current waveform have significant frequency content in such high frequency range, grounding performance degrades during the rising portion of the current pulse in comparison to the power frequency performance.

2) So-called Heidler functions derived to fit experimental data from Berger [51] are used to approximate two lightning current waveforms corresponding, respectively, to typical first and subsequent return strokes, which reproduce the observed concave rising portion of a current waveform front.

3) Simple formula for the impulse coefficient of single vertical and horizontal ground electrodes is deducted from simulation results by a sophisticated computerized method based on the electromagnetic field theory approach [35], which has been previously validated by comparison with experiments.

4) The impulse coefficient is approximated as a linear function of the electrode length for given values of soil resistivity and the current pulse zero-to peak time. Coefficients of the linear functions are approximated for wide range of parameters.

5) The formula is extended for several typical ground electrode arrangements and can be used for a first estimate of the dynamic characteristics of interest in practical design. A simple procedure is given for evaluation of other dynamic characteristics such as: effective length, impulse impedance, and maximal transient ground potential rise.

6) Comparison with previous formulas in [42] reveals agreement between the methods in more resistive earth and for smaller ground electrode lengths. In less resistive earth, for longer ground electrode, and for smaller zero-to-peak times of the lightning current pulses formulas in [42] greatly overestimate the impulse coefficient in comparison with the formula proposed in this paper.

7) The nonlinear phenomena related to the high current ionization of the soil that effectively improve the grounding transient performance are disregarded. In view of all other necessary assumptions, this might be considered as an approximation on the 'safe' side. Therefore, proposed formulas determine the conservative upper bound of the dynamic characteristics.

8) Above mentioned dynamic characteristics are related to the fast transient period only, which for example in high resistive soil lasts only the first few microseconds. After that, in the slow transient period, the performance of the ground electrodes is practically identical with the low frequency performance and is characterized by low frequency grounding resistance $R$. 


\section{APPENDIX A}

FORMULAS FOR LOW FREQUENCY GROUND RESISTANCE OF THE ELECTRODE ARRANGEMENTS IN TABLE III

In this Appendix, formulas for low frequency resistance $R$ for the ground electrode arrangements in Table III are given based on [6]. Similar formulas can be found elsewhere [61], [62]

$$
\begin{aligned}
& R_{1-\text { Rod }}= \frac{\rho}{2 \pi \ell}\left[\ln \left(\frac{4 \ell}{a}\right)-1\right], \quad(\ell \gg a) \\
& R_{2-\text { Rods }}= \frac{1}{2} \frac{\rho}{2 \pi \ell}\left[\ln \left(\frac{4 \ell}{a}\right)-1+\frac{\ell}{D}\right] \\
&(\ell \gg a),(D \geq \ell) \\
& R_{4-\text { Rods }}= \frac{1}{4} \frac{\rho}{2 \pi \ell}\left[\ln \left(\frac{4 \ell}{a}\right)-1+\frac{3.31 \ell}{D}\right] \\
&(\ell \gg a),(D \geq \ell) \\
& R_{1-\text { Wire }}= \frac{\rho}{\pi \ell}\left[\ln \left(\frac{2 \ell}{\sqrt{2 a d}}\right)-1\right] \\
&(\ell \gg a, d \ll \ell) \\
& R_{2-\text { Wires }}= \frac{1}{2} \frac{\rho}{\pi \ell}\left[\ln \left(\frac{2 \ell}{\sqrt{2 a d}}\right)-0.3\right] \\
&(\ell \gg a, d \ll \ell) \\
&= \frac{1}{4} \frac{\rho}{\pi \ell}\left[\ln \left(\frac{2 \ell}{\sqrt{2 a d}}\right)+1.45\right] \\
&(\ell \gg a, d \ll \ell) \\
&\left.R_{4-\text { Wires }}\right]
\end{aligned}
$$

where $a$ is ground electrode radius, $D$ is distance between vertical ground electrodes, and $d$ is depth of burial of horizontal electrodes, all in meters. Also here, $R$ is in ohms and $\rho$ is in ohm-meters

\section{APPENDIX B \\ NUMERICAL EXAMPLE}

As an example, we consider a horizontal four-star electrode arrangement with $\ell=30-\mathrm{m}$ long arms with radius of electrodes 7-mm and depth of burial $0.8-\mathrm{m}$ in soil with resistivity $200-\Omega \mathrm{m}$. Considered strokes have current pulse waveforms as in Fig. 3(a), but have peak values $100-\mathrm{kA}$ for the first stoke and 30-kA for the subsequent stroke.

The coefficients related to the first stroke $\alpha^{F S}$ and $\beta^{F S}$, and the subsequent strokes $\alpha^{S S}$ and $\beta^{S S}$ are (5) and (6)

$$
\begin{aligned}
& \alpha^{F S}=0.025+e^{-0.82(200 \cdot 8.35)^{0.257}}=0.029 \\
& \beta^{F S}=0.17+e^{-0.22(200 \cdot 8.35)^{0.555}}=0.17 \\
& \alpha^{S S}=0.025+e^{-0.82(200 \cdot 0.835)^{0.257}}=0.072 \\
& \beta^{F S}=0.17+e^{-0.22(200 \cdot 0.835)^{0.555}}=0.19 .
\end{aligned}
$$

The effective lengths for the first stroke $\ell_{e f f}^{F S}$ and the subsequent stroke $\ell_{e f f}^{S S}$ are (4)

$$
\begin{aligned}
& \ell_{e f f}^{F S}=\frac{1-0.8 \cdot 0.17}{0.8 \cdot 0.029}=37.2 \mathrm{~m}, \\
& \ell_{e f f}^{S S}=\frac{1-0.8 \cdot 0.19}{0.8 \cdot 0.072}=14.7 \mathrm{~m} .
\end{aligned}
$$

Since for the first stroke $\ell<\ell_{e f f}^{F S}$ then the corresponding impulse coefficient $A^{F S}=1$. For the subsequent stoke $\ell>$ $\ell_{\text {eff }}^{S S}$ and the impulse coefficient is (3):

$$
A^{S S}=0.8 \cdot(0.072 \cdot 30+0.19)=1.9 .
$$

Ground resistivity is (A1-6)

$$
\begin{aligned}
R_{4-\text { Wires }} & =\frac{200}{4 \cdot 3.14 \cdot 30}\left[\ln \left(\frac{2 \cdot 30}{\sqrt{2 \cdot 0.007 \cdot 0.8}}\right)+1.45\right] \\
& =4.1 \Omega .
\end{aligned}
$$

The impulse impedances for the first and subsequent stroke are

$$
\begin{aligned}
Z^{F S} & =R_{4-\text { Wires }} \cdot A^{F S}=4.1 \Omega \\
Z^{S S} & =R_{4-\text { Wires }} \cdot A^{S S}=4.1 \cdot 1.9=7.8 \Omega .
\end{aligned}
$$

Finally, the maximal transient ground potential rise for the first and subsequent stroke is

$$
\begin{aligned}
& V_{m}^{F S}=Z^{F S} \cdot I_{m}^{F S}=4.1 \cdot 100=410 \mathrm{kV} \\
& V_{m}^{S S}=Z^{S S} \cdot I_{m}^{S S}=7.8 \cdot 30=234 \mathrm{kV} .
\end{aligned}
$$

\section{ACKNOWLEDGMENT}

The author is grateful to Dr. A. (Lex), P. J. van Deursen, and Dr. F. Rachidi for stimulating discussions and to Prof. V. Rakov and Dr. F. M. Tesche for helpful suggestions in the early phase of this work, and to three anonymous reviewers whose comments and suggestions helped to improve the manuscript.

\section{REFERENCES}

[1] P. Hasse and J. Wiesinger, Handbookfor Lightning and Grounding (in German), 4th ed. Munich, Germany: Pflaum, 1993.

[2] C. Mazzetti, "Principles of protection of structures against lightning," in The Lightning Flash, V. Cooray, Ed. London, U.K.: IEE, 2003, pp. 503-548.

[3] IEEE Guide for Safety in AC Substation Grounding, IEEE Std. 80-2000, 2000.

[4] P. Chowdhuri, Electromagnetic Transients in Power Systems. New York: Wiley, 1996.

[5] CIGRÉ Guide on Lightning Protection of MV and LV Networks: Part I Common Topics, Tech. Brochure, Paris, France, 2006, CIGRE.

[6] E. D. Sunde, Earth Conduction Effects in Transmission Systems, 2nd ed. New York: Dover, 1968.

[7] L. V. Bewley, Traveling Waves on Transmission Systems, 2nd ed. New York: Wiley, 1951.

[8] R. Rudenberg, Electrical Shock Waves in Power Systems. Cambridge, MA: Harvard Univ. Press, 1968.

[9] E. Y. Ryabkova, Grounding in High Voltage Stations (in Russian). Moscow, Russia: Energia, 1978.

[10] A. P. Meliopoulos, Power System Grounding and Transients. New York: Marcel-Dekker, 1988.

[11] Saint-Privat-d'Alier Research Group, "Eight years of lightning experiments at saint-privat-d'Allier,' Rev. Generale de l'Electricite, vol. 91, no. 9, pp. 561-582, Sep. 1982.

[12] S. Bourg, B. Sacepe, and T. Debu, "Deep earth electrodes in highly resistive ground: Frequency behaviour," in Proc. IEEE Int. Symp. Electromagnetic Compatibility, 1995, pp. 584-589.

[13] Z. Stojkovic, M. S. Savic, J. M. Nahman, D. Salamon, and B. Bukorovic, "Sensitivity analysis of experimentally determined grounding grid impulse characteristics," IEEE Trans. Power Del., vol. 13, no. 4, pp. 1136-1142, Oct. 1998. 
[14] S. Sekioka, H. Hayashida, T. Hara, and A. Ametani, "Measurements of grounding resistances for high impulse currents," Proc. Inst. Elect. Eng., vol. 145, pp. 693-699, Nov. 1998.

[15] A. C. Liew and M. Darveniza, "Dynamic model of impulse characteristics of concentrated earths," Proc. Inst. Elect. Eng., vol. 121, pp. 123-135, Feb. 1974.

[16] J. Wang, A. C. Liew, and M. Darveniza, "Extension of dynamic model of impulse behavior of concentrated grounds at high currents," IEEE Trans. Power Del., vol. 20, no. 3, pp. 2160-2165, Jul. 2005.

[17] M. Ramamoorty, M. M. B. Narayanan, S. Parameswaran, and D. Mukhedkar, "Transient performance of grounding grids," IEEE Trans. Power Del., vol. 4, no. 4, pp. 2053-2059, Oct. 1989.

[18] A. Geri, "Behaviour of grounding systems excited by high impulse currents: The model and its validation," IEEE Trans. Power Del., vol. 14, no. 3, pp. 1008-1017, Jul. 1999.

[19] A. F. Otero, J. Cidras, and J. L. del Alamo, "Frequency-dependent grounding system calculation by means of a conventional nodal analysis technique," IEEE Trans. Power Del., vol. 14, no. 3, pp. 873-878, Jul. 1999.

[20] L. V. Bewley, "Theory and tests of the counterpoise," Elect. Eng., vol. 53, pp. 1163-1172, Aug. 1934.

[21] S. S. Devgan and E. R. Whitehead, "Analytical models for distributed grounding systems," IEEE Trans. Power App. Syst., vol. PAS-92, no. 5 , pp. 1763-1770, Sep./Oct. 1973.

[22] R. Verma and D. Mukhedkar, "Impulse impedance of buried ground wire," IEEE Trans. Power App. Syst., vol. PAS-99, no. 5, pp. 2003-2007, Sep./Oct. 1980.

[23] C. Mazzetti and G. M. Veca, "Impulse behavior of grounded electrodes," IEEE Trans. Power App. Syst., vol. PAS-102, no. 9, pp. 3148-3156, Sep. 1983.

[24] R. Velazquez and D. Mukhedkar, "Analytical modeling of grounding electrodes," IEEE Trans. Power App. Syst., vol. PAS-103, no. 6, pp. 1314-1322, Jun. 1984.

[25] F. Menter and L. Grcev, "EMTP-based model for grounding system analysis," IEEE Trans. Power Del., vol. 9, no. 4, pp. 1838-1849, Oct. 1994.

[26] Y. Liu, M.Zitnik, and R. Thottappillil, "An improved transmission-line model of grounding system," IEEE Trans. Electromagn. Compat., vol. 43, no. 3, pp. 348-355, Aug. 2001.

[27] Y. Liu, N. Theethayi, and R. Thottappillil, "An engineering model for transient analysis of grounding system under lightning strikes: Nonuniform transmission-line approach," IEEE Trans. Power Del., vol. 20, no. 2, pp. 722-730, Apr. 2005.

[28] D. Roubertou, J. Fontaine, J. P. Plumey, and A. Zeddam, "Harmonic input impedance of earth connections," in Proc. IEEE Int. Symp. Electromagnetic Compatibility, 1984, pp. 717-720.

[29] F. Dawalibi, "Electromagnetic fields generated by overhead and buried short conductors, part I-single conductor," IEEE Trans. Power Del., vol. PWRD-1, no. 4, pp. 105-111, Oct. 1986.

[30] F. Dawalibi, "Electromagnetic fields generated by overhead and buried short conductors, part II-ground networks," IEEE Trans. Power Del., vol. PWRD-1, no. 4, pp. 112-119, Oct. 1986.

[31] L. Grcev, "Computation of grounding systems transient impedance," (in Croatian) Ph.D. dissertation, Univ. Zagreb, Zagreb, Croatia, 1986.

[32] L. Grcev and Z. Haznadar, "A novel technique of numerical modelling of impulse current distribution in grounding systems," in Proc. Int. Conf. on Lightning Protection, Graz, Austria, 1988, pp. $165-169$.

[33] L. Grcev and F. Dawalibi, "An electromagnetic model for transients in grounding systems," IEEE Trans. Power Del., vol. 5, no. 4, pp. 1773-1781, Oct. 1990.

[34] L. Grcev, "Computation of transient voltages near complex grounding systems caused by lightning currents," in Proc. IEEE Int. Symp. Electromagnetic Compatibility, 1992, pp. 393-400.

[35] L. Grcev, "Computer analysis of transient voltages in large grounding systems," IEEE Trans. Power Del., vol. 11, no. 2, pp. 815-823, Apr. 1996.

[36] R. Olsen and M. C. Willis, "A comparison of exact and quasi-static methods for evaluating grounding systems at high frequencies," IEEE Trans. Power Del., vol. 11, no. 3, pp. 1071-1081, Jul. 1996.

[37] L. Grcev and M. Heimbach, "Frequency dependent and transient characteristics of substation grounding system," IEEE Trans. Power Del., vol. 12, no. 1, pp. 172-178, Jan. 1997.

[38] A. D. Papalexopoulos and A. P. Meliopoulos, "Frequency dependent characteristics of grounding systems," IEEE Trans. Power Del., vol. PWRD-2, no. 4, pp. 1073-1081, Oct. 1987.
[39] M. Heimbach and L. Grcev, "Grounding system analysis in transients programs applying electromagnetic field approach," IEEE Trans. Power Del., vol. 12, no. 1, pp. 186-193, Jan. 1997.

[40] S. Visacro and A. Soares, "HEM: A model for simulation of lightningrelated engineering problems," IEEE Trans. Power Del., vol. 20, no. 2, pp. 1206-1208, Apr. 2005.

[41] B. R. Gupta and B. Thapar, "Impulse impedance of grounding systems," in Proc. IEEE Power Eng. Soc. Summer Meeting, Paper A 78 563-9., 1978, pp. 1-6.

[42] J. He, R. Zeng, Y. Tu, J. Zou, S. Chen, and Z. Guan, "Laboratory investigation of impulse characteristics of transmission tower grounding devices," IEEE Trans. Power Del., vol. 18, no. 3, pp. 994-1001, Jul. 2003.

[43] J. He, Y. Gao, R. Zeng, J. Zou, X. Liang, B. Zhang, J. Lee, and S. Chang, "Effective length of counterpoise wire under lightning current," IEEE Trans. Power Del., vol. 20, no. 2, pt. 2, pp. 1585-1591, Apr. 2005.

[44] Y. Liu, N. Theethayi, R. Thottappillil, R. M. Gonzalez, and M. Zitnik, "An improved model for soil ionization around grounding system and its application to stratified soil," J. Electrostat., vol. 60, pp. 203-209, 2004.

[45] L. Grcev and V. Arnautovski-Toseva, "Grounding systems modeling for high frequencies and transients: Some fundamental considerations," in Proc. IEEE Bologna Power Tech Conf., 2003, vol. 3, pp. 1-7.

[46] L. Grcev and M. Popov, "On high-frequency circuit equivalents of a vertical ground rod," IEEE Trans. Power Del., vol. 20, no. 2, pt. 2, pp. 1598-1603, Apr. 2005.

[47] H. Rochereau, "Response of earth electrodes when fast fronted currents are flowing out," Response of Earth Electrodes When Fast Fronted Currents are Flowing Out, ser. EDF, B, 1988, pp. 13-22, Bulletin de la Direction des Études et Recherches.

[48] L. Grcev and V. Arnautovski, "Comparison between simulation and measurement of frequency dependent and transient characteristics of power transmission line grounding," in Proc. Int. Conf. Lightning Protection, Birmingham, U.K, 1998, pp. 524-529.

[49] F. Rachidi, W. Janischewskyj, A. M. Hussein, C. A. Nucci, S. Guerrieri, B. Kordi, and J.-S. Chang, "Current and electromagnetic field associated with lightning-return strokes to tall towers," IEEE Trans. Electromagn. Compat., vol. 43, no. 3, pp. 356-367, Aug. 2001.

[50] F. Heidler, "Analytische blitzstromfunktion zur LEMP-berechnung," in Proc. 18th Int. Conf. Lightning Protection, Munich, Germany, 1985, pp. 63-66.

[51] K. Berger, R. B. Anderson, and H. Kroninger, "Parameters of lightning flashes," Electra, no. 41, pp. 23-37, 1975.

[52] Y. Liu, N. Theethayi, and R. Thottappillil, "Investigating the validity of existing definitions and empirical equations of effective length/area of grounding wire/grid for transient studies," J. Electrostat., vol. 65, pp. 329-335, 2007.

[53] J. He, R. Zeng, Y. Tu, J. Zou, S. Chen, and Z. Guan, "Laboratory investigation of impulse characteristics of transmission tower grounding devices," IEEE Trans. Power Del., vol. 18, no. 3, pp. 994-1001, Jul. 2003.

[54] P. L. Bellaschi, "Impulse and 60-cycle characteristics of driven grounds," AIEE Trans., vol. 60, pp. 123-128, 1941.

[55] L. Grcev, "Transient voltages coupling to shielded cables connected to large substations earthing systems due to lightning," in Proc. CIGRÉ Session, Paper 36-201, 1996, pp. 1-6.

[56] E. E. Oettle, "A new general estimation curve for predicting the impulse impedance of concentrated earth electrodes," IEEE Trans. Power Del., vol. 3 , no. 4, pp. 2020-2029, Oct. 1988.

[57] A. M. Mousa, "The soil ionization gradient associated with discharge. of high currents into concentrated electrodes," IEEE Trans. Power Del., vol. 9, no. 3, pp. 1669-1677, Jul. 1994.

[58] L. Grcev and N. Grcevski, "Software techniques for interactive optimization of complex grounding arrangements for protection against effects of lightning," in Proc. Int. Conf. Lightning Protection, Birmingham, U.K., 1998, pp. 518-523.

[59] L. Grcev, "Improved earthing system design practices for reduction of transient voltages," in Proc. CIGRÉ Session, Paper 36-302, 1998, pp. $1-6$.

[60] L. Grcev, "Improved design of transmission line grounding arrangements for better protection against effects of lightning," in Proc. Int. Symp. Electromagnetic Compatibility, Roma, Italy, 1998, pp. 100-103.

[61] E. K. Saraoja, "Lightning earths," in Lightning, R. H. Golde, Ed. New York: Academic, 1977, vol. 2, Lightning Protection, pp. 577-598.

[62] F. M. Tesche, M. V. Ianoz, and T. Karlsson, EMC Analysis Methods and Computational Models. New York: Wiley, 1994, pp. 564-565. 


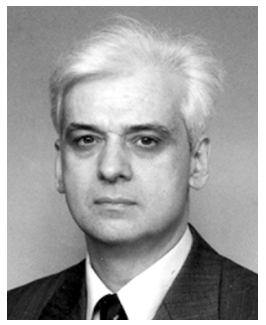

Leonid Grcev (M'84-SM'97) was born in Skopje, Macedonia, in 1951. He received the Dipl.-Ing. degree in electrical engineering from the Saints Cyril and Methodius University, Skopje, Macedonia, in 1978 and the M.S. and Ph.D. degrees in electrical engineering from the University of Zagreb, Zagreb, Croatia, in 1982 and 1986, respectively.

Currently, he is Full Professor with the Faculty of Electrical Engineering at the Saints Cyril and Methodius University, where he has also been Assistant Professor, Associate Professor, and Vice Dean since 1988. From 1978 to 1988 , he was with the Electric Power Company of
Macedonia, Skopje, working in the Telecommunications Department. He has been a Visiting Professor at the Technical University of Aachen, Aachen, Germany, the Eindhoven University of Technology, Eindhoven, The Netherlands; and the Swiss Federal Institute of Technology, Lausanne, Switzerland. He was responsible for several international projects related to electromagnetic compatibility (EMC). His research interests include high-power electromagnetics, EMC, high frequency and transient grounding, lightning, bioelectromagnetics, and EMF health effects. He is author and coauthor of many scientific papers published in reviewed journals and presented at international conferences.

Dr. Grcev is a member of the CIGRE Working Groups related to EMC and lightning protection and has been Chairperson and a member of scientific committees at international conferences. 